\title{
Economic restructuring and employment in Vietnam: A panel Granger causality approach
}

\author{
Nguyen Thanh Trong \\ University of Economics and Law, \\ Vietnam National University Ho Chi Minh City, \\ Vietnam \\ trongnt@,uel.edu.vn
}

\author{
Nguyen Thi Dong \\ University of Economics and Law, \\ Vietnam National University Ho Chi Minh City, \\ Vietnam \\ dongnt@uel.edu.vn
}

\section{Pham Thi Ly}

University of Economics Ho Chi Minh City,

Vietnam

pthy@ueh.edu.vn

Abstract. Economic restructuring is an objective process that alters structure, density, speed and quality of economic relations between sectors and regions to achieve a more reasonable structure for the social and economic development of a country. This process can be very diverse, as sometimes it is not in accordance with rules, thus the results of economic restructuring may depend on subjective or objective factors. Vietnam is a country with an abundant labor force, thus economic restructuring towards creating more jobs for workers is considered a key task of its today's economy. Through the statistical data on the structure of economic sectors and employment in 56 provinces and cities across the country in the period of 1998-2017, combined with the use of Granger causality method, the article examines the relationship between economic restructuring and employment in Vietnam. The research results show that economic restructuring has a positive impact on employment, but there is no statistical evidence for the effect of employment on economic restructuring. The research results are consistent with the reality of economic restructuring and job growth in Vietnam, because when the structure of the economic sector changes suit the development of the world, the labor market in Vietnam also changes to meet the changing needs of the economy. 
Keywords: structural changes, employment, Granger causality, Vietnam.

JEL Classification: J01, O140, C100

\section{INTRODUCTION}

After a serious domestic socioeconomic crisis in the 1980s, Vietnam decided to comprehensively innovate its economic thinking. The main content of this innovation is to abandon the planned economic mechanism and move to the market mechanism with state management. Only less than 10 years after "Doi Moi", Vietnam has made a strong transition, from being an embargoed and surrounded country, it has become one of the world's top food exporters. However, with the limitations of development thinking as well as economic development policies, Vietnam has not succeeded in its plan to become a modern industrial country by 2020. In fact, while digital resources are increasingly proven to be effective, Vietnam still relies on natural resources while promoting its economic growth. As a result, after more than 30 years of innovation, although Vietnam's economic structure has shifted towards reducing the proportion of agriculture and increasing the proportion of industry, this shift is still slow with the number of unskilled jobs increasing, particularly in the agricultural sector. As of 2018, this sector still attracted $37.7 \%$ of the labor force working in the economy overall, of which, up to $86.3 \%$ were simple, untrained labor. This sector generated $17 \%$ of GDP with labor productivity being only $36.6 \%$ of general labor productivity, $33 \%$ of labor productivity in the service sector and $26.4 \%$ of labor productivity in the industrial sector (GSO, 2018).

In order for Vietnam to get closer to its goal of becoming a modern industrialized country, it needs to implement a new growth model: growth based on labor productivity and associated with creating highquality jobs on a social scale. Indeed, for a country with a plentiful labor force like Vietnam, high productivity employment is also the foundation for individual workers to build a good life while more suitable jobs will contribute greatly to social stability. There are many factors that affect employment within an economy, but depending on different stages of economic development, one or several factors emerge to become the key factors. In the current period, economic restructuring can be considered as a leverage factor stimulating employment growth. Moreover, under the impact of the fourth industrial revolution, occupational structure has a close link with technological structure, thus changing employment structure. However, the relationship between economic restructuring and employment is still considered to be a complex relationship because it has many different views on it. On the one hand, most theoretical studies related to economic restructuring and employment confirm that economic restructuring often takes place first and always requires constant redistribution of labor to meet the changing employment needs in various industries. On the other hand, some empirical studies show that employment can be created by the factors other than economic structure as these other factors impact and change the economic structure. In Vietnam, empirical studies on the relationship between economic sector restructuring and employment are still very few. Therefore, to clarify this relationship in the case of Vietnam's economy, this article analyzes the relationship between economic restructuring and employment by means of Granger causality test. This method is quite simple but very practical, it is widely used to study causal effects between two factors. The research data used for this method is taken from the Vietnam Statistical Yearbook over the years.

The remainder of the article is organized as follows. Section 2 presents the relevant literature review. Section 3 discusses the methodology applied. Section 4 describes the data. Section 4 reports the results and provides their discussion. The last section presents conclusions and policy implications. 


\section{LITERATURE REVIEW}

\subsection{Theoretical basis of the relationship between economic restructuring and employment}

Economic restructuring is the correlation among sectors in the whole economy, indicating the reciprocal relationship among sectors in terms of both quantity and quality. Economic restructuring has been always changing along with the development period since the factors that form the economic structure are not fixed. This change can be defined in different ways, but its most common significance is related to the long-term and persistent shift in the structure of economic sectors (Chenery \& Syrquin, 1986; Syrquin, 2010). While the economic structure describes the "static" relationship between the constituent parts at a given time, the structural change shows a "dynamic" change in the proportion of those components compared to earlier periods. Economic restructuring indicates that increased proportion of an industry leads to an increased resources for that sector and vice versa. Accordingly, one of the most important resources for economic growth is that the labor structure will also shift from the labor-surplus sectors to labor-deficit sectors in order to meet the requirements of the sectors. Fisher (1935) suggested that as the economy grows, the economic restructuring towards reducing the proportion of agriculture while increasing the proportion of industry and services due to the change in consumer demand. Accordingly, to meet the increasing demand for industrial goods and services, labors in the agricultural sector will gradually move to the industrial and service sectors. Meanwhile, the agricultural sector could be replaced by machines. The increased use of machinery and new farming methods has enabled farmers to enhance productivity, thereby causing agricultural laborers to move out of rural areas to seek for work in more modern environments.

Based on Ricardo's view of land scarcity and the labor surplus in agriculture (Ricardo, 1817), Lewis (1954) aimed to promote economic growth and create jobs in the early stages of industrialization by transferring all surplus laborers from the agricultural sector to the industrial sector. According to Lewis, the industrial sector creates the majority of wealth for the economy. Different from Lewis, Jorgenson (1961) analyzed the shift of economic structure based on Cobb - Douglas's production function, so he considered technology as a direct and decisive factor to growth in the agricultural sector. Due to technological advances, the marginal productivity of agricultural labor is always greater than zero despite the fixed agricultural land. Therefore, the development in the industrial sector would require more laborers. However, this sector will also be disadvantaged in the growth process if it keeps attracting agricultural laborers without investment in intensive production. In general, the above mentioned literatures have revealed that economic restructuring is an indispensable process in economic growth, and it requires constant redistribution of labor and thus labor restructuring.

\subsection{Empirical studies on the relationship between economic restructuring and employment}

The relationship between economic restructuring and employment has been examined in many empirical works in many countries. Using the data pre- and post- the economic depression $1990-1992$ and 2001 - 2003 in the US, Groshen and Potter (2003) found that economic restructuring plays an important role in generating new jobs for the economy. The authors also concluded that after crisis employment mostly comes from newly established companies operating in the new industries with newly trained workers, which implies that employment growth is not derived from the recovery of the economy, but the changes in economic structure at the recovery stage. Similarly, Nazamuddin (1996) used an econometric method to regressively analyze the relationship between labor restructuring and 
unemployment rate in Indonesia from 1965 to 1996. The results estimated that when the proportion of agricultural employment decreases and the proportion of non-agricultural employment increases, the unemployment rate tends to decrease. Şahin (2020) used the panel cointegration method to examine the impact of the number of industrial robots on employment, minimum wage, and productivity. This study is dependent on the data available from 2006-2017 for 22 OECD countries. The result of the analysis shows that industrial robots' use positively affects both the long-term employment and productivity of the 22 OECD countries. This means that economic restructuring towards modernity will stimulate more job creation

Different from above, using SSA method to measure the impact of economic restructuring on employment quality through labor productivity in different countries, Fagerberg (2000), Timmer and Szirmai (2000), Maris (2019), (Li, Kovacs, \& Choi, 2020) concluded that when in the early stages of industrialization, structural changes have a very strong impact on labor productivity growth. However, when industrialization is successful, this relationship becomes blurred. In this stage, technological factors, rather than restructuring, will be the decisive factor of labor productivity growth. Teal (2011) empirically studies the relationship between economic restructuring and poverty reduction in sub-Saharan Africa. The results show that since 1980, economic restructuring has occurred strongly in the direction of rapidly reducing the proportion of agriculture and manufacturing industry, but the rate of poverty and the level of economic restructuring are not clearly correlated. In addition, through statistical observations, Thompson, Murray, and Jomini (2012) analyze economic restructuring and employment in Australia. The study suggests that the trend of economic restructuring in Australia is a natural consequence of the increase in income, but the process of economic restructuring also costs a considerable amount of retraining, moving and administrative costs.

Using data collected from the small and medium enterprises in Vietnam, Canh (2001) stated that any change in the economic structure will affect the employment structure, and suggested that in order to restructure the economy, the government needs to orient the core industries, and then implement solutions and policies on stimulating investment, training labor force and establish pilot projects on new technology. The development of core industries could be considered the driving force of the development of related sub-industries, thereby creating more jobs. The growth in core industries could result in the collapse and higher unemployment of the weaker industries. Therefore, the number of jobs in the economy created more or less on the shift-ability that increases the opportunities of labor intensive industries due to the adoption of moderate technology, or capital intensive industries due to the application of high technology.

Sharing the same view with Canh (2001), Anh (2007) considered the relationship between economic restructuring and employment through the SSA method. This study identified that at the beginning of the 21 st century, Vietnam still has too many untrained workers and the shortage of jobs is very common. Therefore, the choice of developing capital intensive and highly productive industries did not seem to really fit the country's capacity at the time. Using Granger causality, Ho (2014) also confirmed that GDP structure causes labor restructuring. In addition, Te and Dong (2013) has analyzed quite adequately both in terms of quality and number of jobs as well as the relationship between the two factors of restructuring. economy and employment through the SSA method and elasticity coefficient. 


\section{METHODOLOGY}

\subsection{Research Model}

The Granger causality test was used to measure the relationship between economic restructuring and employment. Moreover, if this relationship exists, Granger causality test will explain whether economic restructuring causes the change in employment or employment causes economic restructuring, or both of them affect each other. Prior to perform Granger causality test, economic restructuring and employment growth were quantitatively calculated as follows:

For employment growth (GL):

$$
G L=\frac{L_{t}-L_{t-1}}{L_{t-1}} * 100 \%
$$

$L_{t}-$ denotes the number of employees in the year $t$.

In terms of economic structure, the study uses the modified Lilien index (MLI) to calculate the annual economic restructuring rate. The MLI index came from the unemployment structural index of Lilien (1982). To evaluate the labor restructuring, Lilien has developed an index to measure the standard devation of employment growth rate by sector for the period from 0 to $t$ and using weights is the share of labor in period t. However, the Lilien formula violated the hypothesis of symmetry and the total of shifting time of the periods. Therefore, this research employed the modified Lilien formula proposed by Stamer (Dietrich, 2009) to calculate the economic restructuring rate as follows:

$$
M L I_{o, t}=\sqrt{\sum_{i=1}^{n} x_{[i o]} \cdot x_{[i t]} \cdot \ln \left(\frac{x_{[i t]}}{x_{[i o]}}\right)^{2}}, x_{[i t]}>0 ; x_{[i o]}>0
$$

$x_{[i \sigma]}$ and $x_{[i t]}$ denote the GDP share of sector $i$ at year 0 and $t . n$ is the number of sectors in the economy.

Granger (1969) indicated the changes in the past could predict the future, not the future could predict the past. Therefore, $\mathrm{X}$ is called to have a causal effect on $\mathrm{Y}$ if $\mathrm{Y}$ can be better explained by using the historical data of both X and Y instead of using only the historical data of Y. Since this research used time-series data, Granger theory only tests the causality of a given unit. To overcome this limitation, Hurlin and Venet (2001) used panel data to test the Granger causality. They pointed out that a panel data provides both cross-sectional and time series information as well as larger sample size. Baltagi (2008) and Greene (2003) also indicated that panel data significantly improves the efficiency of Granger causality tests by increasing the degrees of freedom and reducing the collinearity among explanatory variables. In addition, Greene (2003) stated that panel data allows for more flexibility in modeling of the behavior of cross-sectional units than conventional time-series analysis.

In this research, $\mathrm{X}$ is replaced by an economic restructuring variable (called MLI); Y is replaced by an employment growth variable (called GL). The causality test between two variables will be conducted based on the consideration of the linear panel data model with the following general form:

$$
G L_{i, t}=\sum_{k=1}^{p} \gamma_{i}^{(k)} G L_{i, t-k}+\sum_{k=1}^{p} \beta_{i}^{(k)} M L I_{i, t-k}+v_{i t}
$$

with i $\in[1, \mathrm{~N}]$ and $v_{i t}=a_{i}+\varepsilon_{i, t}$ where $a_{i}$ are individual effect and $\varepsilon_{i, t}$ are error terms, $\varepsilon_{i, t} \in\left[0, \sigma^{2}\right] ; \mathrm{GL}_{\mathrm{i}, \mathrm{t}}$ and $\mathrm{MLI}_{\mathrm{i}, \mathrm{t}}$ are covariance stationary variables; $\mathrm{p}$ is the number of lags. The autoregressive coefficients and regression coefficient slopes are assumed to be constant over time. 
In equation (3), according to Granger, the hypothesis $\mathrm{H}_{0}$ means that MLI has no effect on GL. Therefore, if one or more estimating coefficients of the lags MLI are statistically significant on GL then we have a basis to reject $\mathrm{H}_{0}$ and conclude that MLI has a causal effect on GL.

Weinhold (1996), Nair-Reichert and Weinhold (2001), Erdil and Yetkiner (2004), Hurlin (2004), Emirmahmutoglu and Kose (2011); Dumitrescu and Hurlin (2012), Lopez and Weber (2017), Kim (2018), performed a Granger causality test for panel data with various approaches. In particular, Hulin's approach is a methodology that is quite solid and therefore will be applied in this study with the following hypothesis test steps:

(1) Homogeneous Non Causality hypothesis - HNC

This hypothesis implies that there is no causal relationship for all individuals. Therefore, all slope coefficients associated with the variable $\mathrm{MLI}_{\mathrm{i}, \mathrm{t}}$ are tested to be zero for all individuals and all lags $\mathrm{k}$ through the following two hypotheses:

$$
\begin{aligned}
& H_{0}: \beta_{i}^{(k)}=0, \forall \mathrm{i} \in[1, \mathrm{~N}], \forall \mathrm{k} \in[1, \mathrm{p}] \\
& \mathrm{H}_{1}: \exists(i, k) / \beta_{i}^{(k)} \neq \mathrm{O}
\end{aligned}
$$

The $\mathrm{F}$ statistic is used to test the above hypothesis and is calculated according to the following formula:

$$
F_{h n c}=\frac{\left(R S S_{2}-R S S_{1}\right) / N \cdot p}{R S S_{1} /[N . T-N(1+p)-p]}
$$

$\mathrm{RSS}_{1}$ represents the sum of squared residuals of model (3) and $\mathrm{RSS}_{2}$ denotes the sum of squared residuals of the restricted model. If the realization of this statistic is not significant, the HNC hypothesis is accepted which means that variable MLI is not causing GL in all cross section units. If this is the case, the test procedure stops at this step. Conversely, if the HNC hypothesis can be rejected, the homogeneity of the sample has to be investigated.

(2) Homogeneous Causality bypothesis - HC:

This hypothesis indicates that there is a causal relationship between $\mathrm{MLI}_{\mathrm{i}, \mathrm{t}}$ and $\mathrm{GL}_{\mathrm{i}, \mathrm{t}}$ in all individuals. The null hypothesis and the alternative hypothesis in this case are:

$$
\begin{aligned}
& H_{\mathrm{O}}: \forall \mathrm{k} \in[1, \mathrm{p}] / \beta_{i}^{(k)}=\beta^{k}, \forall \mathrm{i} \in[1, \mathrm{~N}], \\
& \mathrm{H}_{1}: \exists \mathrm{k} \in[1, \mathrm{p}], \exists(i, j) \in[1, \mathrm{~N}] / \beta_{i}^{(k)} \neq \beta^{k}
\end{aligned}
$$

The F statistic is used to test the above hypothesis and is calculated according to the following formula:

$$
F_{h c}=\frac{\left(R S S_{3}-R S S_{1}\right) / p(N-1)}{R S S_{1} /[N . T-N(1+p)-p]}
$$

$\mathrm{RSS}_{3}$ denotes the sum of square residuals of the restricted model by the hypothesis $\mathrm{H}_{0}$ (the model has $\beta_{i}^{k}$ is homogeneous between individuals and $\gamma_{i}^{k}$ is heterogeneous between individuals). If this test is not statistically significant, meaning the HC hypothesis is accepted, then it can be concluded that MLI is the cause of GL in all individuals. If the HC hypothesis can be rejected this does not imply that there is no causal relationship at all, it only implies that the process is non homogenous and that no homogeneous causality can be found. Hence, the next necessary step in this study is the heterogeneous non causality test.

(3) Heterogeneous Non Causality hypothesis - HENC:

The HENC test allows for a number, but not all, of the individual units to have a causal relationship. Therefore, the purpose of this test is to determine which units are causal and which are not causal with the following hypotheses: 


$$
\begin{aligned}
& H_{\mathrm{O}}: \exists \mathrm{i} \in[1, \mathrm{~N}], \forall \mathrm{k} \in[1, \mathrm{p}] / \beta_{i}^{(k)}=\mathrm{O} \\
& \mathrm{H}_{1}: \forall \mathrm{i} \in[1, \mathrm{~N}], \exists \mathrm{k} \in[1, \mathrm{p}] / \beta_{i}^{(k)} \neq \mathrm{O}
\end{aligned}
$$

The corresponding F statistic is:

$$
F_{\text {henc }}^{i}=\frac{\left(R S S_{2, i}-R S S_{1}\right) / p}{R S S_{1} /[N . T-N(1+2 p)+p]}
$$

$R S S_{2, i}$ corresponds to realization of the residual sum of squared obtained in model (3) when one imposes the nullity of the $\mathrm{k}$ coefficients associated to the variable $\mathrm{MLI}_{\mathrm{i}}$ only for individual $\mathrm{i}$. If the HENC hypothesis is accepted, we conclude that there is no relationship between GL and MLI for individual $i$ and vice versa.

\subsection{Data}

This research used data on three major sectors of GDP structure (Agriculture, Industry Construction and Services) and employed workers from the provinces and cities in Vietnam in the period 1998 - 2017. The data were collected by the General Statistics Office of Vietnam (GSO). The GDP structure is based on current prices. In the period 1998 - 2017, the statistics of many provinces and cities were inconsistent or incomplete due to the merger or separation of provinces. Therefore, only 56 out of 63 provinces and cities were selected for empirical analysis to examine the relationship between economic restructuring and employment across administrative units.

Table 1

Descriptive statistics

\begin{tabular}{|l|c|c|c|c|c|}
\hline & MLI & GL & & MLI & GL \\
\hline Observations & 1064 & 1064 & Std. Dev. & 2.93 & 2.63 \\
\hline Medium & 2.49 & 1.72 & Skewness & 5.74 & 0.74 \\
\hline Maximum & 45.82 & 16.47 & Kurtosis & 66.02 & 6.74 \\
\hline Minimum & 0.15 & -12.41 & & & \\
\hline
\end{tabular}

Source: Authors' calculations using GSO data.

\section{EMPIRICAL RESULTS AND DISCUSSION}

\subsection{Unit root test results}

Table 2 presents Unit root test for panel data using LLC tests (Levin-Lin- Chu), IPS (Im, PesaranShin), ADF (Augmented Dickey-Fuller) and PP (Phillips-Perron). The test results indicate that MLI and GL have unit root at $\mathrm{I}(0)$.

In addition, Granger test results are very sensitive to the selection of lags for variables. If the selected lags are less than the actual lags, omitting the appropriate lag variables may bias the results. Conversely, if they are larger, the number of lags that are not appropriate will make the estimates inefficient. The calculation of the optimal lags can also be done through the Akaike or Schwarz information standard (AIC, SIC - Akeke of Schwarz information criterion), provided that the lags value is selected so that AIC or SIC is the smallest. Based on the information standards, the VAR automatically model selected the optimal lags of 3 . 
Unit root tests

\begin{tabular}{|l|c|c|c|c|}
\hline \multicolumn{1}{|c|}{ Variables } & LLC & IPS & ADF & PP \\
\hline \multirow{2}{*}{ MLI } & -15.72 & -15.50 & 447.77 & 495.53 \\
& $(0.000)$ & $(0.000)$ & $(0.000)$ & $(0.000)$ \\
\hline \multirow{2}{*}{ GL } & -20.77 & -19.13 & 546.88 & 829.82 \\
& $(0.000)$ & $(0.000)$ & $(0.000)$ & $(0.000)$ \\
\hline
\end{tabular}

Source: Authors' calculation using GSO data.

\subsection{Granger causality test results}

Table 3 presents the results of homogeneous non-causality hypothesis (HNC) for the case of MLI and GL.

Table 3

Test results for Homogeneous Non-Causality

\begin{tabular}{|c|c|c|}
\hline Lags & MLI $\rightarrow$ GL & GL $\rightarrow$ MLI \\
\hline 1 & $4.67^{* *}$ & 0.00 \\
\hline 2 & $3.21^{* *}$ & $5.84^{* * *}$ \\
\hline 3 & $11.75^{* * *}$ & $7.65^{* * *}$ \\
\hline
\end{tabular}

Note: $*$, ** and $* * *$ are significance levels at $10 \%, 5 \%$ and $1 \%$, respectively

Source: Authors' calculation.

The results show that irrespective of the inclusion of lags, MLI does not significantly affect GL. Meanwhile, GL does not significantly affect MLI at the first lag, but the effect is significant at second lag and third lag. After the null hypothesis of homogeneous non-causality is rejected, the next step is to test the homogeneous causality (HC).

Table 4

Test results for Homogeneous Causality

\begin{tabular}{|l|c|c|c|}
\hline \multicolumn{1}{|c|}{ Lags } & 1 & 2 & 3 \\
\hline $\mathrm{MLI} \rightarrow \mathrm{GL}$ & $6.72^{* * *}$ & $6.08^{* * *}$ & $4.87^{* * *}$ \\
\hline $\mathrm{GL} \rightarrow \mathrm{MLI}$ & 0.25 & 0.36 & 0.13 \\
\hline
\end{tabular}

Note: $*, * *$ and $* * *$ are significance levels at $10 \%, 5 \%$ and $1 \%$, respectively

Source: Authors' calculation.

Table 4 reveals that the HC null hypotheses for causal effect of GL on MLI are accepted, while those of MLI on GL are rejected at three lags. These findings imply that the panel data is heterogeneous and a further analysis at the individual level should be required to examine the causal effects of MLI on GL.

Table 5 reports the results for the heterogeneous non-causality hypothesis. 
Table 5

Test results for Heterogeneous Non-causality Hypothesis (HENC)

\begin{tabular}{|c|c|c|c|c|c|c|c|c|c|}
\hline \multirow{2}{*}{ No. } & \multirow{2}{*}{ Units } & \multicolumn{3}{|c|}{$\mathrm{MLI} \rightarrow \mathrm{GL}$} & \multirow{2}{*}{ No. } & \multirow{2}{*}{ Unit } & \multicolumn{3}{|c|}{$\mathrm{MLI} \rightarrow \mathrm{GL}$} \\
\hline & & $t-1$ & $t-2$ & $t-3$ & & & $t-1$ & $t-2$ & $\mathrm{t}-3$ \\
\hline 1 & Viet Nam & $14.78^{* * *}$ & $8.94 * * *$ & 2.4 & 29 & Da Nang & 0.91 & $6.00 * *$ & 2.67 \\
\hline 2 & Binh Thuan & $11.92^{* * *}$ & $3.46^{*}$ & $4.78^{* *}$ & 30 & Ha Nam & 0 & $3.16^{*}$ & 0.66 \\
\hline 3 & Binh Dinh & $4.69 * *$ & $6.15^{* *}$ & $3.21 *$ & 31 & Ha Tinh & 0.83 & 0.21 & $2.90^{*}$ \\
\hline 4 & HCM city & $4.53^{*}$ & $3.70^{*}$ & $28.93^{* * *}$ & 32 & Hoa Binh & 2.51 & 1.3 & $3.23^{*}$ \\
\hline 5 & Ca Mau & $5.65^{* *}$ & $3.94 * *$ & $5.22^{* *}$ & 33 & Ha Giang & 0.41 & 0.56 & 1.24 \\
\hline 6 & Lam Dong & $7.15^{* *}$ & $3.34 *$ & $3.03^{*}$ & 34 & Lao Cai & 0.43 & 0.08 & 0.32 \\
\hline 7 & Dong Thap & $3.77^{*}$ & $4.28^{* *}$ & $3.53 *$ & 35 & Bac Giang & 0.24 & 0.05 & 0.47 \\
\hline 8 & Binh Thuan & $8.20^{* *}$ & $3.56^{*}$ & $3.25^{*}$ & 36 & Thanh Hoa & 2.3 & 1.36 & 0.89 \\
\hline 9 & Kien Giang & $8.02 * *$ & $3.28^{*}$ & 1.08 & 37 & Quang Binh & 0.58 & 0.31 & 0.26 \\
\hline 10 & Quang Nam & $5.69 * *$ & $6.53 * *$ & 0.76 & 38 & Quang Tri & 0.05 & 0.69 & 1.53 \\
\hline 11 & Kon Tum & $3.69 *$ & $2.91 *$ & 1.41 & 39 & Gia Lai & 0 & 0.76 & 1.39 \\
\hline 12 & Tay Ninh & $7.20 * *$ & $2.86^{*}$ & 1.51 & 40 & Binh Phuoc & 1.76 & 1.75 & 2.14 \\
\hline 13 & Quang Ninh & $6.70 * *$ & $3.77 *$ & 2.56 & 41 & Tra Vinh & 0.43 & 0.29 & 0.29 \\
\hline 14 & Bac Kan & $3.71 *$ & $4.26^{*}$ & 2.13 & 42 & Bac Lieu & 0.81 & 0.69 & 0.31 \\
\hline 15 & Ninh Binh & $4.41^{*}$ & 1.73 & 2.43 & 43 & Cao Bang & 0.13 & 0.31 & 0.41 \\
\hline 16 & Long An & $4.02^{*}$ & 1.86 & 0.75 & 44 & Phu Tho & 0.01 & 0.16 & 0.33 \\
\hline 17 & Dong Nai & $5.69 * *$ & 2.46 & 1.93 & 45 & Vinh Phuc & 2.23 & 1.66 & 0.52 \\
\hline 18 & An Giang & $5.24 * *$ & 2.23 & 1.16 & 46 & Vinh Long & 0.13 & 0.21 & 0.66 \\
\hline 19 & Tien Giang & $3.49 *$ & 1.71 & 1.58 & 47 & Ben Tre & 0.16 & 0.86 & 0.69 \\
\hline 20 & Hai Dương & $3.73^{*}$ & 2.4 & 1.38 & 48 & Yen Bai & 0.86 & 25 & 0.53 \\
\hline 21 & Nam Dinh & 3.07 & $4.60^{* *}$ & $3.36 *$ & 49 & Lang Son & 0.89 & 0.15 & 0.07 \\
\hline 22 & Bac Ninh & 0.25 & $5.22^{* *}$ & $2.92 *$ & 50 & Tuyen Quang & 0 & 0.45 & 0.3 \\
\hline 23 & Sơn La & 2.41 & $6.39 * *$ & $5.81 * *$ & 51 & Quang Ngai & 1.33 & 0.67 & 0.56 \\
\hline 24 & Phu Yen & 1.77 & $5.59 * *$ & $3.18^{*}$ & 52 & Khanh Hoa & 0.17 & 0.22 & 0.21 \\
\hline 25 & Soc Trang & 2.74 & $4.05^{* *}$ & $3.03 *$ & 53 & Binh Duong & 0.01 & 0.52 & 2.06 \\
\hline 26 & Hai Phong & 1.1 & $3.13^{*}$ & $3.77 *$ & 54 & Vung Tau & 0.01 & 1.04 & 0.37 \\
\hline 27 & Thai Nguyen & 2.91 & $2.84 *$ & 1.86 & 55 & Hue & 0.09 & 0.03 & 0.16 \\
\hline 28 & Hung Yen & 2.32 & $3.87^{*}$ & 1.93 & 56 & Thai Binh & 0.8 & 0.54 & 1.67 \\
\hline
\end{tabular}

Note: $*$, ** and $* * *$ are significance levels at $10 \%, 5 \%$ and $1 \%$, respectively Source: Authors' calculation.

The Wald test shows that causal effects of economic restructuring on employment growth at three lags exist for more than $60 \%$ provinces. Meanwhile, the causal effects of MLI on GL are statistically insignificant for the 24 remaining provinces. Therefore, it can be concluded that there exists a relationship between economic restructuring and employment in Vietnam in the direction that economic restructuring can create more jobs for the economy. The results accurately assess the reality of economic development in Vietnam over the past time. Since Vietnam officially entered the market economy, thanks to the adjustment of industry policies, the economic structure has made a positive shift. In GDP, the share of 
agriculture has dropped from $34 \%$ in 1998 to $15 \%$ in 2019, that of industry has risen from $25 \%$ to $41 \%$, and that of services, from $41 \%$ to $44 \%$. Economic structural changes impact also on employment. Annually, 1.2-1.3 million new job opportunities have been created. The proportion of poor households has dropped from over 25\% to $5.7 \%$ between 1998 - 2019. Accordingly, the average life expectancy has increased from 68 to 73.6 years. Much progress has been registered in child protection and care, community health care, and epidemics control (GSO, 2020).

\section{CONCLUSION AND RECOMMENDATIONS}

Economic restructuring and employment are two focal issues in the process of industrialization and modernization in Vietnam. This study assumes that the change in economic structure will have a significant impact on the quantity and quality of labor. When the economic structure changes, the labor market also changes to meet the needs of the economy. Therefore, considering the relationship between these two factors is also find the optimal solution to both solve more jobs for workers and promote the process of economic restructuring to achieve high efficiency. Using available data from $1998-2017$ for 56 provinces and cities in Vietnam to illustrate the relationship between economic restructuring and employment. The Granger causality method is applied. The result of the analysis shows that the economic restructuring has a positive impact on employment, but the relationship in the opposite direction is not statistically significant. Among the provinces that do not show the impact of economic restructuring on employment, there are very developed provinces such as Thua Thien Hue, Khanh Hoa, Vung Tau or Binh Duong. These are the provinces that have developed industries in Vietnam, so the structural shifts from agriculture to industry or service in these provinces in the period of $1998-2017$ are very small. According to Lewis theory, when the share of agriculture decrease to a certain extent, the effect of economic restruring on employment is no longer strong. And so, the situation of these industrial provinces may well have reflected Lewis's theory. Also through the research results, the relevant implications should be paid attention to the following issues:

First, Vietnam should continue to restructure the industries and products of each locality and the whole economy in the direction of developing subsequent (new) products based on existing products. Vietnam should focus on manufacturing, especially export products to promote the country's existing capacity, such as agricultural products and household commodities. These industries can create more jobs and improve the lives of many Vietnamese workers while these products are only produced in the preliminary stage or processing stage. Investment in higher value added stages does not seem to be properly focused. Moreover, in order to be in accordance with the development trend of the world, Vietnam should restructure the domestic economy in the direction of improving development level, labor productivity and quality of life of citizens.

Second, Vietnam should change the investment structure in the way that gives priority to the development of rural industries, as agricultural labor still accounts for a high proportion (more than 40\%) of the total employed workers in Vietnam (GSO, 2018). Therefore, to increase competitiveness in rural areas, attract investment in labor-intensive industries and facilitate labor restructuring, Vietnam must develop manufacturing industries of equipment and machines for agricultural production with clean and high technology. At the same time, in order to meet the demand for high quality human resources for modern industries, Vietnam should rapidly renovate its education system. In particular, higher education must focus and develop critical thinking and creativity capacities.

Third, Vietnam should implement a more effective employment policy to create more jobs. For instance, develop industrial zones that focus on small-scale manufacturing industries using labor-intensive 
production technology; improve infrastructure to attract investment in unskilled labor-intensive services; encourage the development of private sectors, farm household models.

In short, this research employed the Granger causality test to demonstrate the relationship between economic restructuring and employment. However, the limitation is that the paper only considered the industry structure, not the regional or commodity structures. Therefore, further research should be conducted to capture better results and understanding.

\section{REFERENCES}

Anh, N. T. (2007). Assessing the contribution of economic sectors and economic restructuring to labor productivity growth in Vietnam: Ministry of Planning and Investment, Hanoi.

Baltagi, B. (2008). Econometric analysis of panel data: John Wiley \& Sons.

Canh, N. T. (2001). Labor market in Ho Chi Minh city in the progress of economic transformation and the results of the enterprise survey on labor needs. HCM City: Statistical Publishing House.

Chenery, H., \& Syrquin, M. (1986). Typical patterns of transformation. Industrialization growth, 37-83.

Dietrich, A. (2009). Does growth cause structural change, or is it the other way round?: a dynamic panel data analyses for seven OECD countries. Retrieved from

Dumitrescu, E.-I., \& Hurlin, C. (2012). Testing for Granger non-causality in heterogeneous panels. Economic modelling, 29(4), 1450-1460.

Emirmahmutoglu, F., \& Kose, N. (2011). Testing for Granger causality in heterogeneous mixed panels. Economic modelling, 28(3), 870-876.

Erdil, E., \& Yetkiner, I. H. (2004). A panel data approach for income-health causality. In: Citeseer.

Fagerberg, J. (2000). Technological progress, structural change and productivity growth: a comparative study. Structural Change Economic Dynamics, 11(4), 393-411.

Fisher, A. G. (1935). Clash of progress and security: Macmillan and Co. Limited, London.

Granger, C. W. (1969). Investigating causal relations by econometric models and cross-spectral methods. Econometrica: journal of the Econometric Society, 424-438.

Greene, W. H. (2003). Econometric analysis: Pearson Education India.

Groshen, E. L., \& Potter, S. (2003). Has structural change contributed to a jobless recovery? Current Issues in Economics Finance, 9(8).

GSO. (2018). Annual Statistical Yearbook. Retrieved from www.gso.gov.vn

GSO. (2020). Statistical Yearbook of Vietnam 2019: General Statistics Office.

Ho, D. P. (2014). The impact of economic restructuring on the level of economic development and qualit of life. Journal of Economic Development, No.282, 2-14.

Hurlin, C. (2004). Testing Granger causality in heterogeneous panel data models with fixed coefficients. Document de recherche LEO, 5, 1-31.

Hurlin, C., \& Venet, B. (2001). Granger causality tests in panel data models with fixed coefficients. Cabier de Recherche EURISCO, September, Université Paris IX Dauphine.

Jorgenson, D. W. (1961). The development of a dual economy. The economic journal, 71(282), 309-334.

Kim, H. M. (2018). Economic growth and tariff levels in the United States: A Granger causality analysis. Journal of International Studies, 11(4), 79-92.

Lewis, W. A. (1954). Economic development with unlimited supplies of labour.

Li, Q., Kovacs, J. F., \& Choi, G. H. (2020). High-technology employment growth in China: geographic disparities in economic structure and sectoral performance. Economic Change Restructuring, 1-40.

Lilien, D. M. (1982). Sectoral shifts and cyclical unemployment. Journal of political economy, 90(4), 777-793.

Lopez, L., \& Weber, S. (2017). Testing for Granger causality in panel data. The Stata Journal, 17(4), 972-984.

Maris, M. (2019). Structural and productivity shift of industries in Slovakia and Czech Republic: A comparative study. Journal of International Studies, 12(1), 313-323.

Nair-Reichert, U., \& Weinhold, D. (2001). Causality tests for cross-country panels: a New look at FDI and economic growth in developing countries. Oxford bulletin of economics statistics, 63(2), 153-171.

Nazamuddin. (1996). Structural change and unemployment in Indonesia. Colorado State University,

Ricardo, D. (1817). On ThePrinciples of Political Economy and Taxation. London: Dent.

Şahin, L. (2020). Impacts of industrial robot usage on international labor markets and productivity: Evidences from 22 OECD countries. Journal of International Studies, Vol.13(3).

Syrquin, M. (2010). Kuznets and Pasinetti on the study of structural transformation: Never the Twain shall meet? Structural Change Economic Dynamics, 21(4), 248-257. 
Te, N. Q., \& Dong, N. T. (2013). Measuring growth of labor productivity in Vietnam by shift-share analysis of structure of industries. Journal of Economic Development(JED, No. 218), 37-47.

Teal, F. (2011). Structural Transformation, Employment Creation, and Labor Markets: the implications for poverty reduction in sub-Saharan Africa. In: Citeseer.

Thompson, G., Murray, T., \& Jomini, P. (2012). Trade, employment and structural change: The Australian experience. Retrieved from

Timmer, M. P., \& Szirmai, A. (2000). Productivity growth in Asian manufacturing: the structural bonus hypothesis examined. Structural Change Economic Dynamics, 11(4), 371-392.

Weinhold, D. (1996). Investment, growth and causality testing in panels. Economie et Prevision, 126, 163-175. 